\title{
Globalization and the Empowerment of Talent
}

\author{
Dalia Marin, University of Munich \\ Thierry Verdier, DELTA, Paris
}

April 2003

\begin{abstract}
Globalization has been identified by many experts as a new way firms organize their activities and as the emergence of talent as the new stakeholder in the firm. This paper examines the role of trade integration for the changing nature of the corporation. International trade leads to a 'war for talent' which makes it more likely that an organizational equilibrium emerges in the integrated world economy in which control is delegated to lower levels of the firms' hierarchy empowering human capital. Furthermore, trade integration is shown to lead to waves of outsourcing and to convergence in corporate cultures across countries.
\end{abstract}




\section{Introduction}

Many experts have identified globalization as a new way firms organize their activities and as the emergence of human capital as the new stakeholder in the firm. In the last two decades the world economy has gone through a dramatic process of reorganization. The reorganization of the world economy has been characterized by the integration of international trade on the one hand and by the disintegration of production on the other hand. Trade integration has been reflected in the increased share of international trade in GDP in developed countries which almost doubled in the last three decades. Similarly, the disintegration of production can be seen in a new way firms organize their activities (see Feenstra 1998). The organization of production has become global. The international organization of production has been discussed under the heading 'slicing the value chain' (Krugman 1995), 'vertical specialization' (Hummels, Ishii, Yi 2001, Yi 2003), and 'outsourcing' (Feenstra and Hanson 1997) in the trade literature. The global firm produces one input in one location and exports it for refinement to a second location. The refined input then gets further refinement in a third location. During this refinement process, intermediate goods are traded from one location to the next. Thus, an increase in trade in intermediate goods, outsourcing, and an explosion of foreign direct investment are all an expression of the new way firms organize their production.

The spectacular changes in the world economy are accompanied by the reorganization of the corporate sector in industrialized countries. The corporate sector in industrialized countries has witnessed the break up of conglomerates resulting in more specialized and 'downsized' firms. The corporate sector sold unrelated businesses and expanded into related businesses. At the same time firms eliminated layers of middle management by introducing more decentralized decision making inside the corporation and by empowering workers at lower levels of the firm's hierarchy. This has resulted in flatter hierarchies inside the corporation (Holmstrom and Kaplan 2001).

But perhaps the most dramatic change in the last decade is that the nature of the corporation itself is changing. Human capital has become the new stakeholder in the firm. The enterprise of the past was well defined by the ownership of physical assets. The boundaries of the corporation was drawn around these assets. Ownership of physical capital was the primary source of power in the enterprise. These physical assets required huge amounts of investments which went beyond the capacity of management. As a result, the enterprise of the past came to be owned by shareholders. The resulting separation of ownership and control made the agency problem between top management and shareholders the central focus of corporate governance. In contrast, in the enterprise today human capital and talent rather than its plants and machines are the critical 
assets. Improvements in financial markets have made it easier to finance large investments, so the capital intensity is no longer the critical asset of the firm. In today's enterprise, specialized human capital has to create ideas how to do things differently to survive an increasingly competitive environment. Innovative and customized deals are the source of profits today. Thus, the enterprise's talented workforce has become an important source of value to the firm. But this raises new problems of corporate governance. Today's enterprise is no longer a stable entity. In contrast to its machines the firm cannot own its talented workforce. Human capital is mobile and can leave taking with it the firms' value. Thus, the central focus of corporate governance today is how to preserve and protect the boundaries of the firm. The big challenge is how can the firm obtain power over its human capital when it cannot own it. ${ }^{1}$

What accounts for these changes in the world economy on the one hand and in the nature of the corporation on the other? Why has human capital become so important recently? There are two traditional explanations for the increased importance of human capital in the literature: skill-biased technical change and trade integration with low wage countries. Computerization and related technologies have caused firms to switch towards production techniques that are biased in favor of skilled workers (Lawrence and Slaughter 1993). The increase in import competition from low wage countries has shifted resources towards industries that use skilled labor relatively intensive (Leamer 1993). We offer a novel explanation for the increased importance of human capital based on changes in the organization of the firm. Human capital has now more options where to go and it can leave the firm. The improved opportunities for human capital outside the firm happens at the same time as talent becomes the new source of value to the firm. As a result, the organization of the corporation responds to this outside changes by providing incentives for talent to prevent it from leaving the firm. ${ }^{2}$

In this paper we combine the trade explanation for the increased importance of human capital with an explanation based on the theory of the firm to examine how competition for talent can affect the firm's organization on the one hand and how the firm's mode of organization feeds back to the market for talent on the other. For this purpose we introduce the theory of the firm into international trade theory. More specifically, we combine a variant of the Aghion and Tirole (1997) (AT) model of the firm with the Helpman and Krugman (1985) (HK) theory of international trade to explain the emergence of the talent firm. The ATtheory of the firm describes the power struggle inside a single firm but neglects the

\footnotetext{
${ }^{1}$ For an argument along this line see Rajan and Zingales (2000).

${ }^{2}$ Peter Drucker, a well known author of managerial books, argues in his article "The Future of the Company" in the The Economist December 2001 that giving more freedom to what he calls today's prized "knowledge workers" is essential. He cites McKinsey, a consultancy, as argueing that the key battle of this century is the war for talent.
} 
market environment in which the firm operates, in particular competition with other firms for talent. The HK-theory of international trade describes the market environment in which the firm operates, but the firm remains a black box. The integration of the two models will allow us to examine the interaction between trade integration on the one hand and changes in corporate organization on the other. We show that trade integration leads to a 'war for talent' which induces firms to change their organization empowering human capital. The resulting shift in the organizational mix in the economy towards skill intensive firms, in turn, raises the relative demand for human capital in industrialized countries. This increase in the demand for skills is distinct and goes beyond the well known relative increase for skilled workers due to a shift in the output mix towards more skill intensive sectors that typically comes with trade integration with low wage countries.

In a previous paper (Marin and Verdier MV 2002) we introduce the AT-firm into the Dixit and Stiglitz model of monopolisitc competition to examine the interaction between market competition on the one hand and the allocation of power inside the corporation on the other. We find that goods market competition increases the stakes of the firm which makes delegation of power inside the firm more costly. We also show that identical countries may have different corporate cultures depending on the mode of organization other firms choose. In MV (2002) international trade leads to organizational convergence across countries. The organizational equilibrium to which the world economy converges remains, however, undetermined. In the present paper we allow countries to differ in factor endowments which enables us to predict to which organizational equilibrium the integrated world economy will converge. The present paper is also related to Grossman and Helpman (2002) and Antras (2003) who introduce the Hart and Moore-firm into international trade. Their papers focus on the boundary of the firm rather than on the firm as an internal organization as our paper does. Finally, Rajan and Zingales (2001) develop a model of firm organization in which the numbers of hierarchical layers in the corporation act as a wall of protection against the threat of talent leaving and stealing the firm's assets. However, they focus on a single firm and ingnore interactions from goods and factor markets.

The paper is organized in the following sections. In section 2 we develop a two sector general equilibrium model of a closed economy in which firms endogenously choose the mode of organization. The model generates an organizational mix of heterogenous firms which differ with respect to their power allocation inside the corporation. In section 3 we examine how factor markets interact with firms' optimal choice of organization. We show that the mode of firm organization matters for incentives inside the firm at intermediate start up costs of a firm only. Furthermore, we show in this section how the scarcity of human capital in the economy leads to a 'war for talent' which, in turn, determines the mode of 
organization firms choose. We also present in this section what we call the 'Rybzcynsky Theorem of Firm Organization' with a novel feature of the old theorem that arises when firms' mode of organization is endogenous. Section 4 then examines how international trade is affecting corporate organization in two dissimilar countries. We show that international trade may lead to the emergence of the 'talent firm' and to convergence in corporate cultures across countries. Finally, section 5 concludes.

\section{A Model with Endogenous Firm Organiza- tions}

Consider an economy which produces the two goods $X$ and $Y$ with the two factors of production labor $L$ and human capital $H$. Good $X$ is assumed to be more skill intensive than good $Y$. Consumers preferences over the two goods $X$ and $Y$ are

$$
U(X, Y)=X^{a} Y^{1-a} \text { with } X=\left[\int_{0}^{n} x(i)^{\gamma} d i\right]^{\frac{1}{\gamma}} \quad \text { and } \quad 0 \leq \gamma \leq 1
$$

where $x(i)$ is consumption of variety $i$ of good $X$ with $\gamma$ as the degree of product differentiation between different varieties of $X$. Sector $Y$ consists of homogenous goods produced under perfect competition with a constant returns to scale technology given by the unit production $\operatorname{costs} c_{Y}(w, q)$ where $w$ and $q$ are the wage rates for unskilled and skilled labor, respectively. Sector $X$ consists of $n$ horizontally differentiated goods produced under monopolistic competition of the Dixit and Stiglitz type.

\section{1 'Formal' and 'Real' Power in the Firm}

In the $\mathrm{X}$-sector there are $n$ firms with a simple hierarchy consisting of a firm (the principal $\mathrm{P}$ ) and a skilled division manager (the agent $\mathrm{A}$ ). In each firm the $\mathrm{CEO}$ /owner hires a skilled manager to start a firm and employs unskilled workers to produce. There are ex ante $m$ alternative ways to run the firm which differ in terms of production costs. We assume that among these projects only two are worth doing from the perspective of both parties. One project has marginal cost of production $c_{B}$ in terms of unskilled labor and is the "best project" for the $\mathrm{CEO} /$ owner in the sense that it yields the highest possible profit $B$ among the $m$ alternatives. The other project has marginal costs of production $c_{b}$ in terms of unskilled labor and is the "best project" for the agent yielding the highest possible non pecuniary benefit $b$ for the agent. To make things interesting, we assume that the firm produces with lower costs when the principal's best project is implemented $c_{B}<c_{b}=\varphi c_{B}$ with $\varphi>1$ so that there is a potential conflict of 
interest between the firm and her agent. The idea here is that when the agent's best project is implemented he may not choose the cost minimizing project but rather one with high perks for him.

Both parties may acquire information on possible ways to run the firm. However, we assume that the CEO has managerial overload. By spending some unskilled labor resource $L$, the principal learns the payoffs of all projects with probability $E=\operatorname{Min}\left(1, L^{\frac{1}{2}}\right)$ and remains uninformed with probability $1-E .^{3}$ This generates convex costs of information collection $g_{P}(E)=w E^{2}$. Thus, the more information the CEO collects, the higher is the marginal costs of further information. Similarly, by exerting some effort $g_{A}(e)=k e$ with $e \in[0, \bar{e}]$, and $k<b$ the agent learns the payoff of all projects with probability $e$ and remains uninformed with probability $1-e$. We suppose that the principal is risk neutral and that the agent is infinitely risk averse with respect to income. Therefore, the agent is not responsive to monetary incentives and receives a fixed wage $q$ equal to his opportunity costs. All his incentives to gather information on projects will be directly related to the private non pecuniary benefit $b$ he gets from his "best" project.

We denote $\alpha B$ with $(0 \leq \alpha \leq 1)$ as the principal/owner's expected benefit when the agent's preferred project is implemented and $\beta b$ with $(0 \leq \beta \leq 1)$ as the agent's expected benefit when the principal's preferred project is implemented. $\alpha$ and $\beta$ are congruence parameters capturing the degree of conflict between the principal and the agent. The lower $\alpha$ or $\beta$, the more is each party's respective benefit reduced when the other party's project is implemented. $B$ and $b$ are supposed to be known ex ante though the parties do not know ex ante which project yields such payoff. We assume also that, among the $m$ projects, there are some with very high negative payoffs to both parties, implying that choosing randomly a project without being informed is not profitable to both agents who instead prefer to do nothing (project 0 ). This aspect, together with the fact that each uninformed party prefers to rubber-stamp the other informed's party suggestion to do nothing, implies that private information about payoffs gives decision control to the informed party. In this case, the informed party has "real power" rather than "formal power" in the firm. ${ }^{4}$

\footnotetext{
${ }^{3}$ The idea here is that the principal/owner of the firm becomes an owner of the firm not because of her skills but rather because of luck to happen to be born in a family with wealth. An alternative interpretation of the low skill assumption is that the principal uses a low skilled monitoring technology to gather information.

${ }^{4}$ As emphasized by Aghion and Tirole (1997), there are two sources of power in the firm, because it is allocated to the manager "formal power", or because the manager is better informed, "real power".
} 
In the $\mathrm{X}$-sector, firms can choose between three types of organizations, a $\mathrm{P}$ organization in which the $\mathrm{CEO} /$ owner has formal power, an A-organization in which the $\mathrm{CEO} /$ owner delegates formal power to the skilled division manager, and an O-organization in which the $\mathrm{CEO}$ /owner has formal power without an internal hierarchy (in which the agent exerts minimum effort). ${ }^{5}$

The CEO/owner's and the agent's expected payoff under the P-organization when the principal has formal power in the firm are

$$
\begin{aligned}
& u_{P}=E B+(1-E) e \alpha B-w E^{2}-q \\
& u_{A}=E \beta b+(1-E) e b-k e
\end{aligned}
$$

With probability $E$, the $\mathrm{CEO} /$ owner becomes fully informed about her payoffs and picks her preferred project with monetary payoff $B$, while the agent receives only the expected private benefit $\beta b$. With probability $1-E$, the principal remains uninformed about payoffs. The agent may then learn the payoff with probability $e$ and suggest his best project to the principal (who accepts it). The principal receives a monetary payoff $\alpha B$ while the agent gets his best private benefit $b$. Or the agent may remain also uninformed in which case, no project is undertaken. $w E^{2}$ and $k e$ are the costs of information collection of the principal and the agent, respectively.

The first order conditions of the two parties with respect to efforts $E$ and $e$ are

$$
\begin{gathered}
\text { Principal: } B(1-e \alpha)=2 w E \\
\text { Agent: } \begin{aligned}
e= & \bar{e} \text { if } k \leq b(1-E) \\
= & 0 \text { if } k>b(1-E)
\end{aligned}
\end{gathered}
$$

The conditions highlight the trade off between the principal's control and the agent's initiative. The principal supervises more the higher her stake in the project (the larger $B$ ), the larger the conflict of interest between the principal and her agent (the lower $\alpha$ ) and the lower the agent's effort $e$. The agent, in turn, has more initiative the higher her stake (the larger $b$ ) and the lower the principal's interference (the lower $E$ ). Thus, hierarchical control comes with the cost of loosing the agent's initiative.

Consider now the A-organization. In the A-firm the principal delegates formal decision control to the agent. Now, the principal is prevented from overruling the agent's decision when both have acquired information. The advantage of delegating formal power to the agent is that the agent has more initiative to become informed. However, the principal looses now formal as well as real power in the firm, since she has less incentives to become informed.

\footnotetext{
${ }^{5}$ The single managed O-firm corresponds to the Dixit and Stiglitz firm.
} 


\subsection{The Choice of Firm Organization}

We now ask how the principal's control efforts and the agent's initiative inside the firm respond to exogenous changes in the firm's real payoff $B / w$ under the $\mathrm{P}$-organization and under the A-organization, respectively. In Marin and Verdier (2002) we solve for the subgame perfect equilibrium in effort levels $E^{*}, e^{*}$ under each mode of organization to examine how effort incentives respond when real profits gradually increase from low levels $B / w<\widetilde{B}_{P}(\alpha)$, to intermediate levels $\widetilde{B}_{P}(\alpha)<B / w<\widetilde{B}_{A}$, to large levels $\widetilde{B}_{A} \leq B / w$. We summarize the results in the following proposition.

\section{Proposition 1 Let}

$$
\begin{gathered}
\widetilde{B}_{P}(\alpha)=\frac{2(1-k / b)}{1-\bar{e} \alpha} \\
\widetilde{B}_{A}=\frac{2(1-k / b)}{\beta(1-\bar{e})}>\widetilde{B}_{P}(\alpha) \\
\bar{B}(\alpha)=\frac{4 \alpha}{2-\bar{e}}
\end{gathered}
$$

For $B / w<\widetilde{B}_{P}(\alpha)$, the P-organization dominates the A-organization with $e_{P}^{*}=\bar{e}$ and $E_{P}^{*}=\frac{B}{w} \frac{(1-\alpha \bar{e})}{2}$. For $\widetilde{B}_{P}(\alpha)<B / w<\widetilde{B}_{A}$, the A-organization is preferred to the P-organization with $e_{A}^{*}=\bar{e}$ and $E_{A}^{*}=\frac{B}{w} \frac{(1-\bar{e})}{2}$. Finally, for $\widetilde{B}_{A} \leq B / w$, the $P$-organization again dominates the A-organization with $e_{P}^{*}=0$ and $E_{P}^{*}=\frac{B}{2 w}$.

$\widetilde{B}_{P}(\alpha)$ and $\widetilde{B}_{A}$ are the threshold levels of profits at which the agent's initiative is killed under the $\mathrm{P}$-organization and under the A-organization, respectively. Recall that as profits increase the stakes of the principal rises and she controls more potentially destroying the agent's initiative. $\bar{B}(\alpha)$ gives the threshold level of profits at which the $\mathrm{CEO} /$ owner is indifferent between loosing control in the firm while keeping the agent's initiative as in the A-organization and keeping control in the firm but loosing the agent's initiative as in the O-organization.

Intuitively, the mode of organization matters for incentives inside the firm at intermediate levels of profits only. At low and high profit levels, there is no trade-off between control and initiative as is the case in a single AT-firm when the market environment is ignored. At low real profit levels $B / w$, the principal monitors and intervenes little because her stakes are small and she cares little. Therefore, the principal chooses the P-organization as it gives sufficient initiative to her agent. At high profit levels, the principal's stakes are so large that she intervenes even under the A-organization leading to minimum effort by the agent also in the A-organization when the principal delegates formal control to the agent. Therefore, she might as well keep control by choosing the P-organization. 
At intermediate levels of profits there is a trade-off between control and initiative and the principal delegates formal power to her agent to keep his initiative and the A-firm emerges as the optimal mode of organization.

\subsection{Product Markets}

In this section we endogenize the firm's profits $B$ by product market competition of the Dixit and Stiglitz type. Given preferences as expressed in (1), demand for goods $X$ and $Y$ can be written as

$$
Y^{D}=\frac{a}{p_{Y}} R \quad \text { and } \quad x(i)=\frac{(1-a) R}{\int_{0}^{n} p(j)^{-\frac{\gamma}{1-\gamma}}} p(i)^{-\frac{1}{1-\gamma}}=A p(i)^{-\frac{1}{1-\gamma}}
$$

with $p_{Y}$ the price of good $Y, p(i)$ the price of variety $i$ of good $X, R$ is total income, and $A$ is a convenient constant reflecting general equilibrium effects.

Perfect competition in sector $Y$ provides the standard price equals marginal cost relationship

$$
p_{Y}=c_{Y}(w, q)
$$

For product varieties in sector $X$ with marginal cost of production $w . c(i)$ monopolistic profit maximization results in the standard mark-up relationship

$$
p(i)=\frac{w \cdot c(i)}{\gamma}
$$

with firm's profits as

$$
\pi(i)=(1-\gamma) \gamma^{\frac{\gamma}{1-\gamma}} A[w \cdot c(i)]^{-\frac{\gamma}{1-\gamma}}
$$

We can express the firm's/principal's profits as before in the partial equilibrium setting by

$$
\alpha=\varphi^{-\frac{\gamma}{1-\gamma}} \quad \text { and } \quad B=(1-\gamma) \gamma^{\frac{\gamma}{1-\gamma}} A\left[w \cdot c_{B}\right]^{-\frac{\gamma}{1-\gamma}}
$$

The congruence parameter $\alpha$ is now related to the two parameters $\varphi$ and $\gamma$. $\varphi=c_{b} / c_{B}$ gives the cost differential of power in the firm. It measures by how much production costs of the firm $w c(i)$ go up when the agent has control in the firm rather than the principal, $\varphi>1$. The larger $\varphi$ the less cost efficient is the firm under the A-organization compared to the $\mathrm{P}$-organization and thus the more it matters for profits who runs the firm. 


\subsection{Factor Markets}

We turn now to factor markets. In the perfect competitive $Y$ sector the demand for unskilled and skilled labor, respectively are given by $a_{Y}^{L} Y$ and $a_{Y}^{H} Y . a_{Y}^{L}$ and $a_{Y}^{H}$ are the unit input requirements in sector $Y$ and are given by shepard's lemma

$$
a_{Y}^{L}(w, q)=\frac{\partial c_{Y}(w, q)}{\partial w} \quad \text { and } \quad a_{Y}^{H}(w, q)=\frac{\partial c_{Y}(w, q)}{\partial q}
$$

Denote $\theta_{L}(w, q)$ and $\theta_{H}(w, q)$ as the unskilled and skilled labor share cost in the $Y$ sector

$$
\theta_{L}(w, q)=\frac{w a_{Y}^{L}(w, q)}{p_{Y}} \quad \text { and } \quad \theta_{H}(w, q)=1-\theta_{L}(w, q)=\frac{q a_{Y}^{H}(w, q)}{p_{Y}}
$$

Firms in the $X$ sector hire a skilled manager to find and supervise a production project and employ unskilled workers to produce. The firm's output in the monopolistic competitive $X$ sector is given by

$$
x(i)=\gamma^{\frac{1}{1-\gamma}} A[w c(i)]^{-\frac{1}{1-\gamma}}
$$

From this, we may derive the total demand for unskilled labor in the $X$ sector for each organizational equilibrium (depending on whether firms will choose the P-organization, A-organization, or the O-organization) using the law of large numbers and the fact that the probability for a firm to run a production project with unit costs of unskilled labor $c(i)$ is also the fraction of firms having such a cost structure. Note that the aggregate demand for unskilled labour in the $X$ sector depends on the organizational mix of real $\mathrm{P}$-firms and real A-firms (as compared to formal P-firms and formal A-firms), because the firm's mode of organization affects its production costs and with it its individual labour demand. Note further that even under an organizational equilibrium with formal P-firms there will be a share of real A-firms in the $X$ sector, when the principal in these firms decides not to get informed about projects in which case the agent has real power (a real A-firm) even when the principal has formal power in the firm (a formal P-firm).

- Labor demand under a formal P-organization with agent's effort

Consider first the aggregate labor demand for unskilled labor under the Porganization. It can be written as

$$
L_{P}^{D}=n\left[E_{P}^{*} c_{B} x_{B}+\left(1-E_{P}^{*}\right) e_{P}^{*} c_{b} x_{b}\right]+n\left(E_{P}^{*}\right)^{2}+a_{Y}^{L} Y
$$

The demand for unskilled labor has three components, the labor demand from the monopolistic X-sector given by $n[.$.$] , the labor demand from the competitive$ Y-sector given by $a_{Y}^{L} Y$, and the labor demand from the principal's unskilled monitoring activity $n\left(E_{P}^{*}\right)^{2}$. The first term in the first bracket is the demand 
for unskilled labor from real P-firms for which the principal's preferred project is implemented. Their fraction is (by the law of large numbers) $E_{P}^{*}$ under the P-organization with the firm's individual labor demand $c_{B} x_{B}$. Similarly, the second term in the first bracket is the demand for unskilled labor from real Afirms for which the agent's preferred project is implemented. Their fraction is $\left(1-E_{P}^{*}\right) e_{P}^{*}$ under the P-organization with the firm's individual labor demand $c_{b} x_{b}$. In the second bracket of the RHS, the term $E_{P}^{* 2}$ captures the unskilled labor of direct monitoring by the principal. We assume here that the principal can use a monitoring technology produced with unskilled labor to supervise projects. Substituting $x_{B}, x_{b}$ and $c_{b}$ gives

$$
L_{P}^{D}=n A \gamma^{\frac{1}{1-\gamma}} w^{\frac{-1}{1-\gamma}}\left[E_{P}^{*}+\left(1-E_{P}^{*}\right) \alpha e_{P}^{*}\right]\left[c_{B}\right]^{-\frac{\gamma}{1-\gamma}}+n\left(E_{P}^{*}\right)^{2}+a_{Y}^{L} Y
$$

which can be rewritten to

$$
L_{P}^{D}=n \frac{\gamma}{1-\gamma}\left(\frac{B}{w}\right)\left[E_{P}^{*}+\left(1-E_{P}^{*}\right) \alpha e_{P}^{*}\right]+n\left(E_{P}^{*}\right)^{2}+a_{Y}^{L} Y
$$

Similarly, the aggregate demand for human capital under the P-organization is given by

$$
H_{P}^{D}=n+a_{Y}^{H} Y
$$

The first term $n$ reflects the fact that each monopolistic firm hires a skilled agent to run the firm. The second term is the demand for skilled labor from sector $Y$.

Using the goods market equilibrium for sector $Y$ and (2) we get

$$
Y=\frac{a}{p_{Y}} R=\frac{a}{1-a} \frac{\int_{0}^{n} p(j)^{-\frac{\gamma}{1-\gamma}}}{p_{Y}} A=\frac{a}{1-a}\left(\frac{B}{p_{Y}}\right) \frac{n}{1-\gamma}\left[E_{P}^{*}+\left(1-E_{P}^{*}\right) \alpha e_{P}^{*}\right]
$$

Denote $\nu_{P}=E_{P}^{*}+\left(1-E_{P}^{*}\right) \alpha e_{P}^{*}$ as the 'organizational mix' of firms in the $X$ sector. Substituting and regrouping terms we then have

$$
\begin{aligned}
L_{P}^{D} & =n \frac{\nu_{P}}{1-\gamma}\left(\frac{B}{w}\right)\left[\gamma+\frac{a}{1-a} \theta_{L}(w, q)\right]+n\left(E_{P}^{*}\right)^{2} \\
H_{P}^{D} & =n+n \frac{\nu_{P}}{1-\gamma}\left(\frac{B}{w}\right) \frac{a}{1-a} \theta_{H}(w, q) \frac{w}{q}
\end{aligned}
$$

These labor demand functions hold for regions of real profit levels $B / w$ for which the P-organization is an equilibrium. Using Proposition 1 from the previous section (6) and (7) hold for

$$
B / w<\tilde{B}_{P}(\alpha) \text { and } E_{P}^{*}=\frac{(1-\bar{e} \alpha)}{2} \frac{B}{w}, e_{P}^{*}=\bar{e}
$$


Substituting (8) in (6), finally results in the following aggregate demand for labor and human capital

$$
\begin{aligned}
L_{P}^{D} & =n \frac{\nu_{P}}{1-\gamma}\left(\frac{B}{w}\right)\left[\gamma+\frac{a}{1-a} \theta_{L}(w, q)\right]+n\left(\frac{B}{w}\right)^{2} \frac{(1-\bar{e} \alpha)^{2}}{4} \\
H_{P}^{D} & =n+n \frac{\nu_{P}}{1-\gamma}\left(\frac{B}{w}\right) \frac{a}{1-a} \theta_{H}(w, q) \frac{w}{q}
\end{aligned}
$$

with the 'organizational mix'

$$
\nu_{P}=\frac{(1-\bar{e} \alpha)^{2}}{2}\left(\frac{B}{w}\right)+\bar{e} \alpha
$$

As can be seen aggregate factor demand depends on the number of firms in the $\mathrm{X}$-sector $n$, on the organizational mix of real $\mathrm{P}$-firms and real A-firms in the $\mathrm{X}$-sector $\nu_{P}$, and on real profits $B / w$ determining the size of the $\mathrm{Y}$-sector and the principal's monitoring activity inside firms in the $\mathrm{X}$-sector.

\section{- Labor demand under a formal A-organization}

Consider now the aggregate demand for unskilled and skilled labor under the A-organization in which the principal delegates formal power to her skilled agent. As before, it can be written as

$$
\begin{aligned}
L_{A}^{D} & =n\left[e_{A}^{*} c_{b} x_{b}+\left(1-e_{A}^{*}\right) E_{A}^{*} c_{B} x_{B}\right]+n\left(E_{A}^{*}\right)^{2}+a_{Y}^{L} Y \\
H_{A}^{D} & =n+a_{Y}^{H} Y
\end{aligned}
$$

The first term in the first bracket is the demand for unskilled labor from firms in which the agent has control. Their fraction is $e_{A}^{*}$ with the firm's individual labor demand $c_{b} x_{b}$. The second term in the first bracket is the demand for unskilled labor from firms in which the principal has real power in the firm under the formal A-organization. Their fraction is $\left(1-e_{A}^{*}\right) E_{A}^{*}$ with the firm's individual labor demand $c_{B} x_{B}$. The term $E_{A}^{* 2}$ is the unskilled labor cost of direct monitoring by the principal and $a_{Y}^{L} Y$ is again the demand for unskilled labor from sector $Y$.

We can rewrite these as

$$
\begin{aligned}
L_{A}^{D} & =n \frac{\nu_{A}}{1-\gamma}\left(\frac{B}{w}\right)\left[\gamma+\frac{a}{1-a} \theta_{L}(w, q)\right]+n\left(E_{A}^{*}\right)^{2} \\
H_{A}^{D} & =n+n \frac{\nu_{A}}{1-\gamma}\left(\frac{B}{w}\right) \frac{a}{1-a} \theta_{H}(w, q) \frac{w}{q}
\end{aligned}
$$

with $\nu_{A}=e_{A}^{*} \alpha+\left(1-e_{A}^{*}\right) E_{A}^{*}$, as the " organizational mix" in an A-equilibrium. These labor demand functions hold for regions of profits $B / w$ for which the Aorganization is an equilibrium. Using again Proposition 1, this holds when 


$$
\widetilde{B}_{P}(\alpha)<B / w<\bar{B}(\alpha) \text { and } E_{A}^{*}=\frac{B(1-\bar{e})}{2 w}, e_{A}^{*}=\bar{e}
$$

Substituting (12) in (11) gives the following aggregate demand for labour and human capital

$$
\begin{aligned}
L_{A}^{D} & =n \frac{\nu_{A}}{1-\gamma}\left(\frac{B}{w}\right)\left[\gamma+\frac{a}{1-a} \theta_{L}(w, q)\right]+n\left(\frac{B}{w}\right)^{2} \frac{(1-\bar{e})^{2}}{4} \\
H_{A}^{D} & =n+n \frac{\nu_{A}}{1-\gamma}\left(\frac{B}{w}\right) \frac{a}{1-a} \theta_{H}(w, q) \frac{w}{q}
\end{aligned}
$$

with

$$
\nu_{A}=\frac{(1-\bar{e})^{2}}{2}\left(\frac{B}{w}\right)+\bar{e} \alpha
$$

- Labor demand under an O-organization with no agent's effort

Finally, we consider the aggregate unskilled and skilled labor demand under the O-organization. Recall that in the O-organization the $\mathrm{CEO} /$ principal runs the firm herself without the agent's cooperation. As before, it can be written as

$$
\begin{aligned}
L_{0}^{D} & =n\left[E_{0}^{*} c_{B} x_{B}\right]+n\left(1+\left(E_{0}^{*}\right)^{2}\right)+a_{Y}^{L} Y \\
H_{0}^{D} & =n+a_{Y}^{H} Y
\end{aligned}
$$

with $E_{0}^{*}$ as the fraction of firms in which the agent does not do anything useful. $\left(1+\left(E_{0}^{*}\right)^{2}\right)$ captures the unskilled labor costs of monitoring of the principal, given that she is the only one that collects information. Again, this can be rewritten to

$$
\begin{aligned}
L_{0}^{D} & =n \frac{\nu_{0}}{1-\gamma}\left(\frac{B}{w}\right)\left[\gamma+\frac{a}{1-a} \theta_{L}(w, q)\right]+n\left(E_{0}^{*}\right)^{2} \\
H_{0}^{D} & =n+n \frac{\nu_{0}}{1-\gamma}\left(\frac{B}{w}\right) \frac{a}{1-a} \theta_{H}(w, q) \frac{w}{q}
\end{aligned}
$$

with $\nu_{0}=E_{0}^{*}$ as the "organizational mix" in the O-regime. These labor demand functions hold for regions of profits for which the O-organization emerges as an equilibrium given by

$$
B / w>\bar{B}(\alpha) \text { and } E_{0}^{*}=\frac{B}{2 w},
$$

Again substituting (16) in (15) finally yields the following aggregate demand for labor and human capital

$$
\begin{aligned}
L_{0}^{D} & =n \frac{\nu_{0}}{1-\gamma}\left(\frac{B}{w}\right)\left[\gamma+\frac{a}{1-a} \theta_{L}(w, q)\right]+n \frac{1}{4}\left(\frac{B}{w}\right)^{2} \\
H_{0}^{D} & =n+n \frac{\nu_{0}}{1-\gamma}\left(\frac{B}{w}\right) \frac{a}{1-a} \theta_{H}(w, q) \frac{w}{q}
\end{aligned}
$$


with

$$
\nu_{0}=E_{0}^{*}=\frac{B}{2 w}
$$

The market clearing conditions for unskilled and skilled labor can then be generally stated as

$$
\begin{gathered}
L_{i}^{D}=L \text { for } i \in\{P, A, 0\} \\
H_{i}^{D}=H \text { for } i \in\{P, A, 0\}
\end{gathered}
$$

\subsection{Free Entry}

Firms enter the X-sector until profits are driven down to cover the fixed start up costs of a firm. The free entry conditions for the three possible organizational equilibria are

$$
\begin{aligned}
\text { P-organization with } e_{P}^{*} & =\bar{e} \\
\qquad u_{P}^{*} & =w\left(E_{P}^{*}\right)^{2}+\bar{e} \alpha B-q=0
\end{aligned}
$$

The first two terms are the equilibrium expected current profits of the firm. $q$ is the start-up cost of a firm. To start a firm the principal has to hire a skilled agent as a manager. After substituting the condition can be restated as

$$
\frac{(1-\bar{e} \alpha)^{2}}{4}\left(\frac{B}{w}\right)^{2}+\bar{e} \alpha\left(\frac{B}{w}\right)=\frac{q}{w}
$$

\section{A-organization with $e_{A}^{*}=\bar{e}$}

$$
u_{A}^{*}=w\left(E_{A}^{*}\right)^{2}+\bar{e} \alpha B-q=0
$$

which can be rewritten to

$$
\frac{(1-\bar{e})^{2}}{4}\left(\frac{B}{w}\right)^{2}+\bar{e} \alpha\left(\frac{B}{w}\right)=\frac{q}{w}
$$

O-organization with $e_{0}^{*}=0$

$$
u_{0}^{*}=w\left(E_{0}^{*}\right)^{2}-q=0
$$

which can be rewritten to

$$
\frac{1}{4}\left(\frac{B}{w}\right)^{2}=\frac{q}{w}
$$




\section{Corporate Organization and the Scarcity of Talent}

We are now in a position to describe the equilibrium under autarky. The analysis proceeds in three stages. First, we analyze the factor market clearing free entry equilibria treating firms' organizational choice as given. Then we derive how the factor endownment of a country affects its firms' mode of organization. Finally, we determine how international trade is affecting these organizational equilibria.

\subsection{Equilibrium in a Closed Economy}

We start now to describe the equilibrium under autarky contingent on the organizational equilibrium which will emerge inside the firm.

- Equilibrium with P-organization and $e_{P}^{*}=\bar{e}$

The endogenous variables determining the equilibrium in the P-regime are the stakes of the firm $B / w$, the "organizational mix" of firms in the X-sector $\nu_{P}$, the number of monopolistic firms $n$, and the wage gap between skilled and unskilled labor $q / w$. Using the two factor market clearing conditions (9), the condition determining the organizational mix (10), and the free entry condition (19) and accounting for the fact that because of the homogeneity property of the cost functions, the unskilled and skilled labor cost shares $\theta_{L}(w, q)=1-\theta_{H}(w, q)$ depend on the relative wage $q / w$ only, we get

$$
\frac{L}{H}=\frac{\frac{\nu_{P}}{1-\gamma}\left(\frac{B}{w}\right)\left[\gamma+\frac{a}{1-a} \theta_{L}(q / w)\right]+\left(\frac{B}{w}\right)^{2} \frac{(1-\bar{e} \alpha)^{2}}{4}}{\frac{\nu_{P}}{1-\gamma}\left(\frac{B}{w}\right) \frac{a}{1-a} \frac{\left[1-\theta_{L}(q / w)\right]}{q / w}+1}
$$

which can be simplified to

$$
\frac{L}{H}=\bar{\Theta}_{P}\left(\frac{B}{w}\right)
$$

with $\bar{\Theta}_{P}\left(\frac{B}{w}\right)$ as the required real profit level which guarantees factor market clearing. $\bar{\Theta}_{P}$ will be upward sloping under the following assumptions.

$$
\text { Assumption A.1 : } \quad \gamma+\frac{a}{1-a}\left(2 \theta_{L}-1\right)>0
$$

Good $Y$ is sufficient unskilled labor intensive, ie $\theta_{L}$ is large enough.

$$
\text { Assumption A.2: } \quad \sigma_{Y} \geq 1
$$

The elasticity of substitution $\sigma_{Y}$ between skilled and unskilled labor for good $Y$ is larger than $1 .{ }^{6}$ Assumption A.2 implies that the cost share of unskilled

\footnotetext{
${ }^{6}$ There is quite a large variation of estimates of this "macro" elasticity in the empirical literature. So far, the consensus seems to be that the mean estimate of this elasticity is larger than 1 (Freeman 1986).
} 
labor for good $Y \theta_{L}$ is increasing in $q / w$. We then show in the Appendix that under assumptions A.1 and A.2, $\bar{\Theta}_{P}$ is increasing in $B / w$. Note also that $\lim _{B / w \rightarrow \infty} \bar{\Theta}_{P}(B / w)=+\infty$ and $\bar{\Theta}_{P}(0)=0$

- Equilibrium with A-organization and $e_{P}^{*}=\bar{e}$

Similarly, with the same procedure as before using the two factor market clearing conditions (13), the condition for the organizational mix (14), and the free entry condition (20), we get the free entry organizational A-equilibrium as

$$
\frac{L}{H}=\frac{\frac{\nu_{a}}{1-\gamma}\left(\frac{B}{w}\right)\left[\gamma+\frac{a}{1-a} \theta_{L}\right]+\left(\frac{B}{w}\right)^{2} \frac{(1-\bar{e})^{2}}{4}}{\frac{\nu_{A}}{1-\gamma}\left(\frac{B}{w}\right) \frac{a}{1-a} \frac{\left[1-\theta_{L}\right]}{q / w}+1}
$$

which simplifies to

$$
\frac{L}{H}=\bar{\Theta}_{A}\left(\frac{B}{w}\right)
$$

$\bar{\Theta}_{A}$ is again upward sloping in $B / w$ under assumptions A.1 and A.2. Furthermore, $\lim _{B / w \rightarrow \infty} \bar{\Theta}_{A}(B / w)=+\infty$ and $\bar{\Theta}_{A}(0)=0$. Also, because of $\nu_{A}<\nu_{P}$, $\bar{\Theta}_{A}\left(\frac{B}{w}\right)<\bar{\Theta}_{P}\left(\frac{B}{w}\right)$ for all values of $B / w>0$.

- Equilibrium with O-organization and $e_{0}^{*}=0$

Analogously, the free entry organizational O-equilibrium is given by

$$
\frac{L}{H}=\frac{\frac{\nu_{0}}{1-\gamma}\left(\frac{B}{w}\right)\left[\gamma+\frac{a}{1-a} \theta_{L}\right]+\left(\frac{B}{w}\right)^{2} \frac{1}{4}}{\frac{\nu_{0}}{1-\gamma}\left(\frac{B}{w}\right) \frac{a}{1-a} \frac{\left[1-\theta_{L}\right]}{q / w}+1}
$$

which can be restated as

$$
\frac{L}{H}=\bar{\Theta}_{0}\left(\frac{B}{w}\right)
$$

with the same properties as before for $\bar{\Theta}_{0}$.

Finally, for small values of $B / w$, the $\bar{\Theta}$ schedules can be ranked as $\bar{\Theta}_{0}(B / w)<$ $\bar{\Theta}_{A}(B / w)<\bar{\Theta}_{P}(B / w)$. For large values of $B / w$, it holds that $\bar{\Theta}_{0}(B / w)>$ $\bar{\Theta}_{A}(B / w)$. Hence, there is a least one value of $B / w$ such that the two curves $\bar{\Theta}_{0}(B / w)$ and $\bar{\Theta}_{A}(B / w)$ cross each other. For expositional ease, we will assume that they only cross once. A typical example that satisfies such a case is when $\theta_{L}=1$ and the competitive sector $Y$ uses unskilled labor only.

\subsection{The Human Capital Constraint}

Next, we want to examine how a country's relative factor endownment $\frac{L}{H}$ determines the mode of organization its firms choose. This is done in Figure 1. The three schedules $P, A$ and $O$ on the right side of Figure 1 correspond to $\bar{\Theta}_{P}(B / w)=L / H, \bar{\Theta}_{A}(B / w)=L / H$ and $\bar{\Theta}_{0}(B / w)=L / H$ that we have just derived. They give the real operating profits in terms of unskilled labor consistent 
with factor market clearing under a $\mathrm{P}-$, A-, and O-organizational equilibrium, respectively. The three schedules are upward sloping in $\frac{L}{H}$, because as the country becomes more unskilled labor rich the relative wage $w / q$ falls and real profits $B / w$ have to increase to restore factor market equilibrium. An increase in real profits increases the demand for unskilled labor for two reasons. First, production in the $\mathrm{X}$ - and $\mathrm{Y}$-sector expands, and this expansion is biased towards the less skill intensive Y-sector. This is a standard Rybzcynsky effect on the output mix. Second, the firm controls more as her stakes rise with an increase in profits. Recall, that the principal's monitoring activity is assumed to be low skill intensive. Via this channel the factor endownment of a country has a direct influence on the behavior inside the firm.

The A-schedule lies above the P-schedule, since A-firms in which the skilled agent runs the firm, are more skill intensive organizations than P-firms. Thus, it requires larger real profits to clear factor markets in an A-equilibrium compared to a P-equilibrium. The relative demand for unskilled labor is lower in an Aequilibrium, because in A-firms the principal monitors less and firms' ouput is lower compared to P-firms. Thus, for a given relaxation in the resource constraint real profits have to increase by more in the A-equilibrium compared to the $\mathrm{P}$ equilibrium to still satisfy the factor market clearing condition.

The O-curve is above the A-curve for low levels of $\frac{L}{H}$ and below the A-curve for high levels of $\frac{L}{H}$. O-firms and A-firms cannot be ranked unambigiously in terms of their factor intensity, because of two conflicting effects. At low levels of $\frac{L}{H}$, the stakes of the firm are low and thus the principal exerts little control in the Ofirm. This in turn generates few opportunities for profitable production projects compared to A-firms. As production is using unskilled labor, the demand for unskilled labor is then smaller in the O-equilibrium compared to the A-equilibrium. Thus, a relatively larger increase in real profits is required to absorb the relative excess supply of unskilled labor in the O-equilibrium. At large levels of $\frac{L}{H}$, the stakes of the firm are large and the relative demand for unskilled labor is larger in the O-equilibrium than in the A-equilibrium both because output per firm and information collection by the principal are larger in O-firms compared to A-firms. Therefore, real profits need to increase by less in the O-equilibrium compared to the A-equilibrium to clear the factor market. 


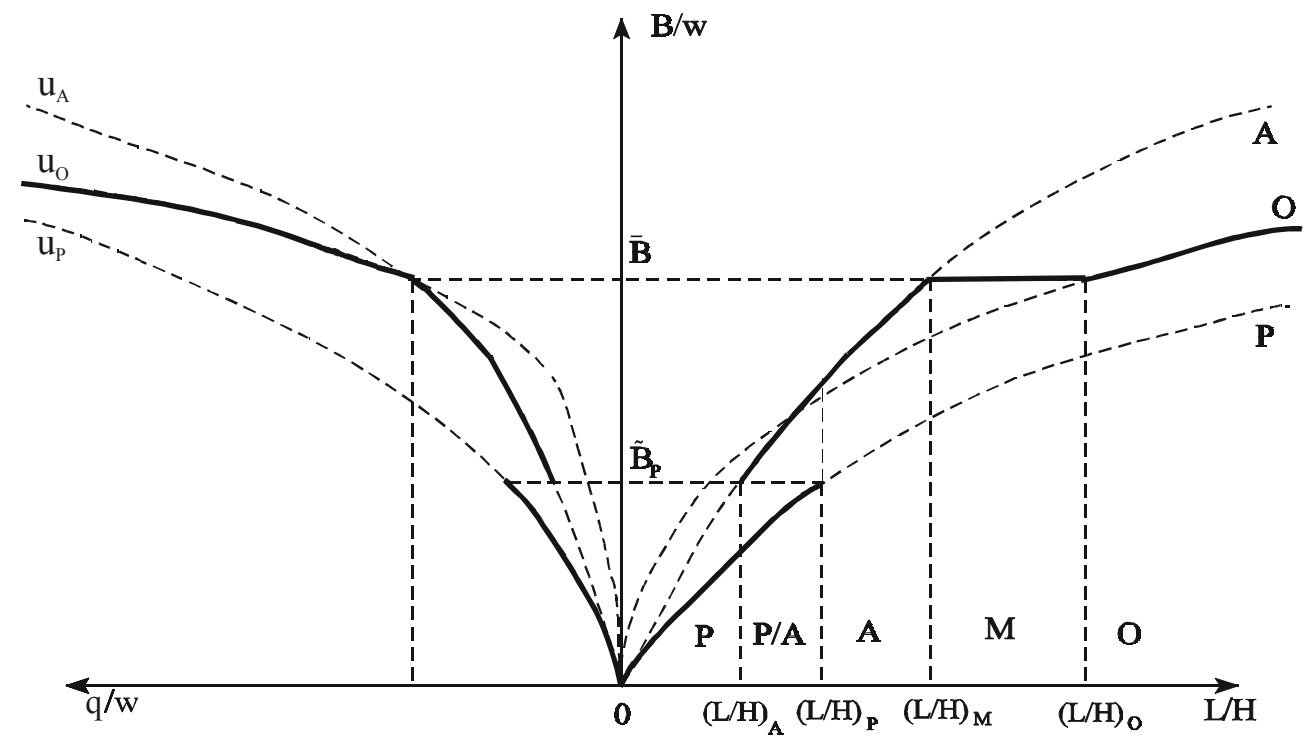

Figure 1: Factor Endowment and Organizational Equilibrium

The left side diagram of Figure 1 gives the free entry conditions $u_{P}^{*}, u_{A}^{*}$, and $u_{0}^{*}$ for P-, A-, and O-firms, respectively from (19), (20), and (21) which relate the firms' real operating profits $B / w$ to their fixed costs of market entry. Starting a firm involves hiring a skilled agent for information collection who is paid a wage $q$. Thus, the firm's start up costs in terms unskilled labor are given by the wage gap $q / w$. The wage gap $q / w$ increases with $B / w$, because when real operating profits increase new firms want to enter the market. Firms can enter and run a firm only by hiring a skilled agent. Thus, market entry is constraint by the amount of available human capital $\mathrm{H}$ in the country. Firms compete for the scarce talent of agents available in the economy to start new firms. As the resource constraint for human capital binds, market entry cannot happen and the relative wage for talent $q / w$ increases to meet the demand for skilled agents.

Returning to the right side diagram of Figure 1 we turn now to the firms' optimal choice of organization which from Proposition 1 is determined by the two horizontal lines $\widetilde{B}_{P}$ and $\bar{B}$. The $\widetilde{B}_{P}$-line captures the cost of having control in the firm in terms of the loss of the agent's initiative. $\widetilde{B}_{P}$ gives the threshold level of profits at which the agent's initiative is killed under the P-organization. The $\bar{B}$ line captures the gain of having control in the firm in terms of the firm's profits. $\bar{B}$ gives the threshold level of profits at which the principal is indifferent between the O-firm in which she runs the firm without the agent's cooperation and the A-firm in which the principal delegates power to her agent. From Proposition 1 we know that for profit levels below the $\widetilde{B}_{P}$-line the benefit of control outweights its costs and firms choose the P-organization. In fact, at these levels of profits there are no costs of control, since the agent's initiative can be kept alive under the P-organization. For profit levels $B / w$ inbetween the $\widetilde{B}_{P^{-}}$and $\bar{B}$-lines, the 
cost of control outweights the benefit and the firms go for the A-organization. Delegating control allows to maintain the agent's initiative, while at the same time delegation of power does not cost too much in terms of profits. For profit levels above the $\bar{B}$-line, the benefit of control again outweights its costs and firms choose the O-organization. Real profits are so large that the principal kills the initiative of the agent even under the A-organization, while delegating power incurs large losses in profits.

Clearly, an organizational equilibrium has to be both consistent with factor market clearing and consistent with the firm's optimal choice of organization. Hence, building on Proposition 1, we derive the pattern of symmetric organizational equilibria in the following proposition.

Proposition 2 Let the following factor endowments $(L / H)_{P},(L / H)_{A},(L / H)_{M}$, and $(L / H)_{O}$ be given by $(L / H)_{P}=\bar{\Theta}_{P}\left(\widetilde{B}_{P}(\alpha)\right),(L / H)_{A}=\bar{\Theta}_{A}\left(\widetilde{B}_{P}(\alpha)\right),(L / H)_{M}=$ $\bar{\Theta}_{M}(\bar{B}(\alpha))$ and $(L / H)_{O}=\bar{\Theta}_{0}(\bar{B}(\alpha))$. Then,for $L / H<(L / H)_{A}$, all firms adopt a $P$-organization;

for $L / H \in\left[(L / H)_{A},(L / H)_{P}\right]$, there are multiple equilibria, firms either adopt a $P$-organization or an A-organization;

for $L / H \in\left[(L / H)_{P},(L / H)_{M}\right]$, all firms adopt an A-organization;

for $L / H \geq(L / H)_{O}$, all firms adopt an O-organization.

These organizational equilibria are depicted in bold in Figure 1. The right diagram of Figure 1 illustrates how factor market clearing interacts with the firm's optimal choice of organization. A factor market clearing equilibrium Porganization is along the bold P-curve below the $\widetilde{B}_{P}$-line in the region of $L / H$ in $\left[0,(L / H)_{P}\right]$. Below the $\widetilde{B}_{P}$-line firms choose the P-organization and along the P-curve operating real profits are such that firms have an incentive to enter as P-firms. Moreoever, they are able to find a talented agent to start a firm, since the market for talent is in equilibrium along the P-curve. Similarly, a factor market clearing A-equilibrium is along the bold A-curve in the region of $L / H$ in $\left[(L / H)_{A},(L / H)_{M}\right]$ in between the two profit lines $\widetilde{B}_{P}$ and $\bar{B}$. In beetween the two latter lines firms choose the A-organization and along the A-curve firms enter as A-firms and find enough talent to hire. Finally, a factor market clearing equilibrium with O-organizations is along the bold O-curve above the $\bar{B}$-line in the region of $L / H$ in $\left[(L / H)_{0}, \infty\right]$. Above the $\bar{B}$-line firms choose the O-organization and along the O-curve firms enter with O-organizations and find the personnel to do so.

The bold line in the right diagram of Figure 1 describes the nature of the factor market clearing organizational equilibria as a function of a country's factor endownment. The left diagram of Figure 1 gives the free entry conditions and the firm's start up costs which correspond to these equilibria. With an increase in 
$L / H$, the equilibrium firm organization moves from the P-firm in which power is concentrated at the top of the corporate hierarchy, to the A-firm in which the talented manager runs the firm, and finally to the single managed O-firm in which the firm is run without her manager's cooperation. ${ }^{7}$ As the country becomes more unskilled labor rich, the fixed costs of market entry increase and thus firms require larger operating real profits to enter the market. With the increase in the relative wage for skilled labor $q / w$, it becomes more expensive to start a firm. This means that the stakes of the firm rise with an increase in $L / H$. We move up along one of the three $u$-curves in the left diagram contingent on which organizational equilibrium emerges. As the stakes rise the principal's incentive to take control in the firm increases. ${ }^{8}$

Initially, at a low ratio of $L / H$, the start up costs of a firm are not too large. Therefore, the principal monitors only little and does not kill the initiative of the agent under the P-organization. Hence, firms choose the latter. We move up along the bold $u_{P^{-}}$-curve in the left side diagram and the bold P-curve in the right side diagram. However, when the ratio of $L / H$ keeps increasing and takes intermediate levels in the region of $\left[(L / H)_{A},(L / H)_{M}\right]$, the relative wage for manager talent and thus the firm's required stakes to enter the market are high enough to kill the initiative of the agent under the P-organization. There is a trade-off between control and initiative for the firm. The principal delegates power to the skilled agent to prevent the loss of his enthusiasm and the Aorganization emerges as a free entry factor market clearing equilibrium. We move up along the bold $u_{A}$-curve in the left side diagram and the bold A-curve in the right side diagram. The empowernment of talent stops to work as an incentive devise for initiative, however, when the ratio of $L / H$ keeps increasing further in the region of $\left[(L / H)_{0}, \infty\right]$. The start-up costs and stakes of the firm are now so large that the firm wants control no matter what and the single managed O-firm without the agent's initiative emerges as the equilibrium organization. We move up along the bold $u_{0}$-curve in the left side diagram and the bold O-curve in the right side diagram.

Note that in the range of factor endowments of $\left[(L / H)_{A},(L / H)_{P}\right]$ the model produces multiple organizational equilibria. One equilibrium mode of organization is the P-firm and another equilibrium is the A-organization. At this region of factor endowments the attractiveness between these two modes of organizations depends on the organizational decision taken by other firms in the market. Each

\footnotetext{
${ }^{7} \mathrm{~A}$ move from the P-organization to the A-organization in which the skilled manager runs the firm can be thought of as the firm outsourcing the division to her manager.

${ }^{8}$ The monotone increasing function between the relative factor endownment of a country $\mathrm{L} / \mathrm{H}$ and the free entry profit level $\mathrm{B}^{*} / \mathrm{w}$ shows how the AT model of the firm speaks to the $\mathrm{HK}$ theory of international trade. With an increase in the ratio $\mathrm{L} / \mathrm{H}$ the required profits to enter the market and thus the free entry stakes of the firm rise. Via this channel the factor endownment of a country affects the behavior inside the firm.
} 
firm individually would choose the A-organization at this range of $L / H$, since in between the two horizontal lines $\widetilde{B}_{P}$ and $\bar{B}$ the A-organization is optimal. However, when the firm anticipates that all other firms will choose the P-organization, then she also anticipates that the equilibrium relative wage for skilled labor $q / w$ will be lower as well. Thus, an individual A-firm with larger marginal costs of production $c_{b}>c_{B}$ compared to $\mathrm{P}$-firms will then have to pay a larger wage to its unskilled workers $w$. As a result, the firm anticipates that with production costs $w . c_{b}$ it will not be profitable to enter with an A-organization. Thus, the firm's best choice will be to choose a P-organization as well. Similarly, when the firm anticipates that all other firms will choose the A-organization, then she expects a larger equilibrium relative wage for skilled labor and thus the firm can profitably enter with an A-organization as well. Note further, that the multiplicity of equilibria disappears for low and large values of $L / H$ because in each of these cases the start up costs and thus the entry stakes of the firm are either so low or so large that all firms will find it profitable to either choose the P-organization at levels of $L / H$ below $(L / H)_{A}$ or to opt for the A-organization at levels of $L / H$ above $(L / H)_{P}$ whatever the other firms' organizational modes. There is no need to coordinate actions among firms in these cases.

Finally, note that for $L / H$ in the region of $](L / H)_{M},(L / H)_{O}[\operatorname{mixed}$ equilibria with A-organizations and O-organizations exist. If a pure equilibrium with A-organizations existed in this range, it had to be consistent both with factor market clearing (ie. $B / w$ on the $A$-curve with $\bar{\Theta}_{A}(\bar{B} / w)=L / H$ ) and with the optimal choice of firm organization ( ie. $B / w$ below $\bar{B}(\alpha)$ ). As can be seen from Figure 1, this is clearly impossible as $\bar{\Theta}_{A}($.$) is increasing in B / w$ and $\bar{\Theta}_{A}(B / w)=L / H>(L / H)_{M}=\bar{\Theta}_{A}(\bar{B}(\alpha))$. Similary, if a pure equilibrium with O-organizations existed, it had to be consistent both with factor market clearing (ie. $B / w$ on the $O$-curve with $\left.\bar{\Theta}_{O}(B / w)=L / H\right)$ and with the optimal firm organization ( ie. $B / w$ above $\bar{B}(\alpha)$ ). Again, this is clearly impossible as $\bar{\Theta}_{O}($.) is increasing in $B / w$ and $\bar{\Theta}_{O}(B / w)=L / H<(L / H)_{O}=\bar{\Theta}_{O}(\bar{B}(\alpha))$. Hence, for factor endowments in this region a mixed equilibrium with $\mathrm{A}$ - and $\mathrm{O}$-organizations exist. We explore these mixed organizational equilibria in more detail in the next section.

\subsection{Rybzcynsky and Mixed Organizational Equilibria}

By definition, in a mixed organizational equilibrium firms are indifferent between different modes of organizations. We know from Proposition 1 that whenever it is feasable (at sufficiently low real profit levels of $B / w \leq \widetilde{B}_{P}$ ) the $P$-organization is preferred over the other two organizations. Therefore, a real profit level at which firms are indifferent between the P-organization and the A-organization does not exists. Hence, the only candidate mixed equilibrium is between A-firms and O-firms. Firms will be indifferent between these two modes of organizations 
when they lead to the same operating profits given by $B / w=\bar{B}(\alpha)$.

Denote then $\lambda$ as the fraction of firms choosing an $A$-organization in such a candidate mixed equilibrium. Using the law of large numbers aggregate factor demand is then

$$
\begin{aligned}
L_{M}^{D} & =\lambda L_{A}^{D}+(1-\lambda) L_{0}^{D} \\
H_{M}^{D} & =\lambda H_{A}^{D}+(1-\lambda) H_{0}^{D}
\end{aligned}
$$

with $L_{A}^{D}$ and $L_{0}^{D}$ as given in (13) and $H_{A}^{D}$ and $H_{0}^{D}$ as given in (17) and calculated for the indifference profit level $B / w=\bar{B}(\alpha)$.

The free entry condition for both A-firms and O-firms for the indifference profit level $\bar{B}(\alpha)$ is

$$
\frac{(1-\bar{e})^{2}}{4}(\bar{B}(\alpha))^{2}+\bar{e} \alpha(\bar{B}(\alpha))=\frac{1}{4}(\bar{B}(\alpha))^{2}=\frac{q}{w}
$$

which pins down uniquely the wage gap $q / w$ in a mixed organizational equilibrium. $B / w=\bar{B}(\alpha)$ fixes uniquely the organizational mix of firms under the two organizations $\nu_{A}$ and $\nu_{0}$ given in (14) and (18). Finally, since $\theta_{L}(w, q)$ is a function of the wage gap $q / w$ only, it follows that the aggregate factor demands $L_{A}^{D}$, $H_{A}^{D}, L_{0}^{D}$, and $H_{0}^{D}$ from A-firm and O-firms, respectively in such a mixed organizational equilibrium are also constant. The factor market clearing conditions can then be written as

$$
\begin{aligned}
\frac{L}{H} & =\mu \bar{\Theta}_{A}(\bar{B}(\alpha))+(1-\mu) \bar{\Theta}_{0}(\bar{B}(\alpha)) \\
& =\mu\left(\frac{L}{H}\right)_{M}+(1-\mu)\left(\frac{L}{H}\right)_{O}
\end{aligned}
$$

with

$$
\left.\mu=\frac{\lambda H_{A}^{D}}{\lambda H_{A}^{D}+(1-\lambda) H_{0}^{D}} \in\right] 0,1[
$$

The following proposition summarizes the previous discussion and describes the nature of the mixed organizational equilibria. 
Proposition 3 The Rybzcynsky Theorem of Firm Organization i) For each $L / H \in](L / H)_{M},(L / H)_{O}[$, there exists a unique mixed equilibrium with A-organizations and O-organizations in which factor prices are fixed and do not depend on factor endownments. The fraction of firms choosing an A-organization is given by

$$
\lambda^{*}=\frac{\mu H_{0}^{D}}{(1-\mu) H_{A}^{D}+\mu H_{0}^{D}}
$$

with

$$
\mu=\mu\left(\frac{L}{H}\right)=\frac{\left(\frac{L}{H}\right)_{O}-\frac{L}{H}}{\left(\frac{L}{H}\right)_{O}-\left(\frac{L}{H}\right)_{M}}
$$

ii) For each $L / H \in](L / H)_{M},(L / H)_{O}$ [, the organizationalmix of firms is biased toward the unskilled intensive O-organization

$$
\frac{d\left(1-\lambda^{*}\right)}{1-\lambda^{*}}>\frac{d\left(\frac{L}{H}\right)}{\frac{L}{H}}>0>\frac{d \lambda^{*}}{\lambda^{*}}
$$

iii) For all $L / H$ outside the interval $](L / H)_{M},(L / H)_{O}[$ a mixed organizational equilibrium does not exists.

The intuition for Proposition 3 can again be illustrated with the help of Figure 1. The mixed equilibrium with A-organizations and O-organizations is in the region $\left[(L / H)_{M},(L / H)_{O}\right]$ in which the $\bar{\Theta}_{M^{-}}$-curve becomes horizontal at the profit level $\bar{B}$ at which the A-organization and the O-organization both lead to the same level of profits. As the relative supply of unskilled labor increases in this range, factor prices $q / w$ remain fixed. To understand why this is happening, we turn to the positively sloped part of the A-curve at a profit level just below $\bar{B}$. As we move up along the A-curve in this range, production in the $\mathrm{X}$-sector and Y-sector expands with an increase in $L / H$. Output becomes less skill intensive as the expansion is biased toward the unskilled intensive Y-sector. This is a standard Rybzcynsky effect on the output mix. Relative demand for unskilled labor increases as a result and factor prices $q / w$ adjust along the $u_{A^{-}}$curve in the left side diagram of Figure 1.

This sectoral reallocation along the A-curve takes place until we reach the indifference profit level $\bar{B}$. At this profit level a shift in the organizational mode takes place with an increase in $L / H$. Firms change their organization from A to $\mathrm{O}$. This organizational change makes both production as well as monitoring activity less skill intensive. As a result, relative demand for unskilled labor increases. We move from a skill intensive organization in which the skilled agent runs the firm to an unskilled labor intensive organization in which the principal runs the firm. Moreoever, the organizational shift from $\mathrm{A}$ to $\mathrm{O}$ leads to an increase in output 
per firm in the X-sector which uses unskilled labor. If all firms would switch to the O-organization at once, there would be an excess demand for unskilled labor. In order for factor markets to clear, a fraction of firms $\lambda$ remains with the skill intensive A-organization easing the demand for unskilled labor. The relative resource constraint $\mu$ captures the relative excess demand for unskilled labor when all firms switch to the O-organization which, in turn, determines the required fraction of firms staying with the A-organization to obtain factor market equilibrium. Rather than factor prices, the fraction of firms with an Aorganization adjusts to guarantee factor market clearing. Thus, as we move along the flat part of the $\bar{\Theta}_{M}$-curve, factor prices remain fixed and the organizational mix changes rather than the output mix as is the case along a movement on the A-curve. The organizational change is biased toward the unskilled intensive Oorganization. This is a Rybzcynsky effect on the organizational mix rather than on the output mix as is usual in a standard Heckscher-Ohlin model in which the firm organization is exogenous.

\section{Trade and the Emergence of the Talent Firm}

We can now proceed to analyze how international trade is affecting a country's corporate organization. Suppose two countries North $N$ and South $S$ which differ in their factor endownments open trade with one another at zero transportation cost. $N$ is endowed with $L_{N}$ and $H_{N}$ and $S$ with $L_{S}$ and $H_{S}$. Suppose that the North is human capital rich and the South is labor rich with $L_{N} / H_{N}<L_{S} / H_{S}$. Denote $L=L_{N}+L_{S}$ and $H=H_{N}+H_{S}$ as the world factor endowments.

In order to understand how trade is affecting the equilibrium choice of corporate organization, we consider a trading equilibrium with factor price equalization. Hence, the integrated world economy is equivalent to a single economy under autarky with factor endowments $L=L_{N}+L_{S}$ and $H=H_{N}+H_{S}$. We illustrate the effect of trade with the help of Figure 2 which reproduces Figure 1 for trade integration with factor price equalization. Suppose the factor endowment of North $L_{N} / H_{N}$ happens to be below $(L / H)_{A}$ and that of the South $L_{S}$ $/ H_{S}$ is above $(L / H)_{O}$. Thus, under autarky firms in $N$ adopt a hierarchical Porganization in which the CEO has power at the top of the corporate hierarchy, while firms in $S$ choose the single managed O-organization in which the CEO runs the corporation without her talented manager's cooperation. The corresponding relative wages for skilled labor $q / w$ in the two countries are given by points $\mathrm{N}$ and $\mathrm{S}$ in the left diagram of Figure 2. What happens now when these two economies start to trade?

We know that the factor endowment of the integrated world economy $(L / H)_{W}$ will be somewhere between that of country $N$ and country $S$. From Prospositions 1 and 2 we also know that depending on which $(L / H)_{W}$ emerges in the world 
trading equilibrium, there are various organizational equilibria possible. One such outcome is a factor endowment of the integrated world economy $(L / H)_{W}$ in the interval $\left[(L / H)_{P},(L / H)_{M}\right]$ in Figure 2 in which firms adopt an A-organization in the world trading equilibrium. How is this coming about? In the human capital rich North international trade leads to stronger specialization in the skill intensive monitoring activity resulting in a resource reallocation toward the skill intensive $\mathrm{X}$-sector. As a result, the relative wage for unskilled labor falls and real operating profits in terms of unskilled labor increase $B / w$. This, in turn, makes entry into the $\mathrm{X}$-sector more attractive. However, firms can enter and run a firm only by hiring a skilled agent. Thus, market entry is constraint by the amount of available talent in the country. Firms compete for the scarce talent of agents and bid up the relative wage for talent. As the start up costs of a firm increase, firms require larger real operating profits to enter the market. As the stakes of the firm rise, the principal takes more control inside the corporation potentially destroying her agent's intiative. To maintain her engagement in the firm the principal delegates formal power to the skilled agent resulting in an organizational change from the P-firm to the A-firm.

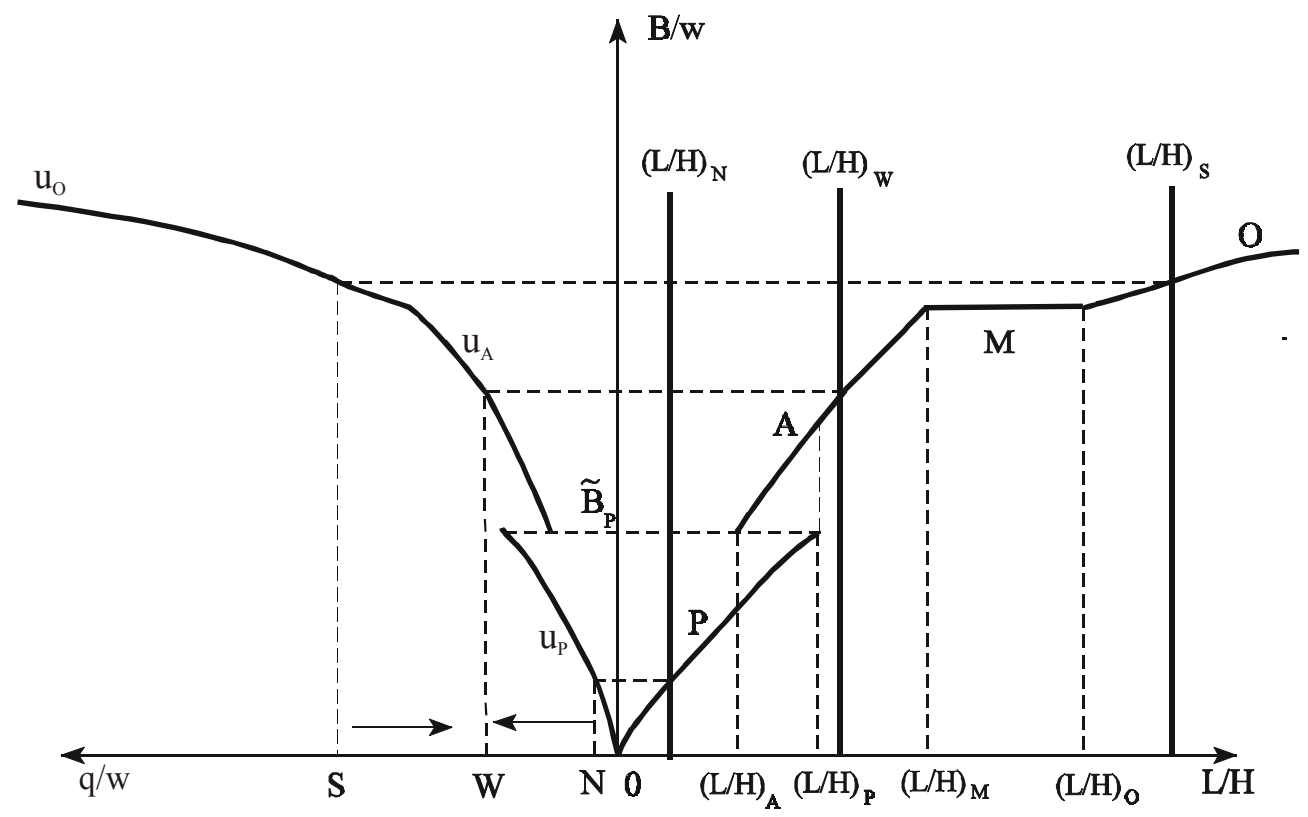

Figure 2: Trade Integration and Organizational Change

In the industrialized North international trade puts pressure on the demand for talent for three distinct reasons: skill-bias sectoral reallocation, the 'war for talent', and skill-bias organizational change. The first effect is the conventional skill bias resource reallocation from the $\mathrm{Y}$ - to the $\mathrm{X}$-sector which increases the demand for skills for the usual reasons. ${ }^{9}$ In the 'war for talent' effect new firms

\footnotetext{
${ }^{9}$ The resource reallocation effect is degenerated in our model because we assume for sim-
} 
enter the market and compete with incumbent firms for scarce manager talent in order to start a firm. The organizational change effect from the P-firm to the A-firm involves a shift from a low skill intensive organization to a skill intensive organization. Each of these mechanisms lead to an increase in the relative demand for skills resulting in a widening of the wage gap in the North from point $\mathrm{N}$ to point $\mathrm{W}$ in the left diagram of Figure 2.

In the labor rich South trade leads to a resource reallocation toward the unskilled intensive Y-sector and to a decline in real operating profits in terms of unskilled labor with some firms exiting from the X-sector lowering the start-up cost of firms. As there is less at stake in firms in the South, the CEO/owner in these firms cares less about control and more about gaining the talented agent's initiative. Hence, she delegates formal power to him resulting in a shift from the O-firm to the A-firm. In the South, international trade eases the demand for skills because of an unskilled bias resource reallocation and the exit of some firms from the X-sector releasing manager talent. The increase in the relative demand for skills due to the skill bias organizational change from the O-firm to the A-firm is of second order. As a result, in the South the wage gap declines from point $\mathrm{S}$ to point $\mathrm{W}$ in the left diagram of Figure 2.

\subsection{Convergence in Corporate Cultures}

We have just seen that the North as well as the South converge to an A-organizational equilibrium in which the skilled manager has power in the corporation when both regions each start with a different corporate organization of a $\mathrm{P}$-firm and an Ofirm, respectively. How likely is it that organizational convergence will take place? We answer this question by using the technique of the edgeworth box of world factor endowments applied by Helpman and Krugman (1985). More specifically, for a given size of world factor endowments $L=L_{N}+L_{S}$ and $H=H_{N}+H_{S}$, the parallelogram in Figure 3 represents the distributions of factor endowments between the two economies which characterize a trade equilibrium with factor price equalization replicating the integrated world economy. We reverse now the question we ask in Figure 2 by starting the analyses with the assumption that in the integrated world economy an equilibrium with A-organizations has emerged. We now ask what distributions of factor endowments between North and South under autarky are consistent with this A-organizational equilibrium of the integrated world economy?

The vector $N Y$ of the parallelogram is the employment level of factors $L$ and $H$ in the $Y$-sector and the vector $Y S$ is the employment level of the two factors in the $X$-sector. Sector $Y$ is less skill intensive than sector $X$. Because we start

plicity that the $\mathrm{X}$-sector uses no skilled labor in production, but only in monitoring. 
with the assumption that in the integrated world economy an equilibrium with A-organizations has emerged, the diagonal $N S$ represents the factor endowment ratios of the integrated world economy $(L / H)_{W}$ at which both regions choose the A-organization represented by $\{A ; A\}$. The light rays from the origin of North $N(L / H)_{A}$ and $(L / H)_{P}$ are the threshold levels of factor endowment ratios at which an organizational change occurs which correspond to those in Figure 2. Similarly, the light rays from the origin of South $S(L / H)_{M}$ and $(L / H)_{O}$ are the threshold levels of factor endowment ratios at which an organizational shift occurs which again correspond to those in Figure 2. By symmetry we describe only what happens below the diagonal where the North is human capital rich. Thus, the area between the diagonal and the ray $(L / H)_{P}$ give distributions of factor endowments consistent with a world trade equilibrium of A-organizations in which firms in the North choose the A-organization under autarky. Similarly, the area between the ray $(L / H)_{P}$ and the ray $(L / H)_{A}$ give distributions of factor endowments consistent with a world trade equilibrium of A-organizations in which firms in the North choose either an A-organization or a P-organization. Finally, the area between the ray $(L / H)_{A}$ and the bold line of the parallelogram give distributions of factor endowments consistent with a world trade equilibrium of A-organization in which firms in the North choose the P-organization. A similar reasoning can be done from the perspective of the South. Thus, $\{P ; O\}$ describes the distribution of factor endowments at which $N$ has a $P$-equilibrium and $S$ has an $O$-equilibrium under autarky. $\{A / P, O\}$ describes a situation in which North chooses either A-firms or P-firms, and South chooses O-firms.

As the factor content of consumption can be represented by a point on the diagonal, the volume of intersectoral trade increases with the distance to the diagonal. The further away from the diagonal the endowment point of the two countries, the larger the difference between North and South in factor composition and thus the larger the volume of trade. Thus, organizational convergence is the more likely the more dissimilar the two countries and the larger their trade volume. 


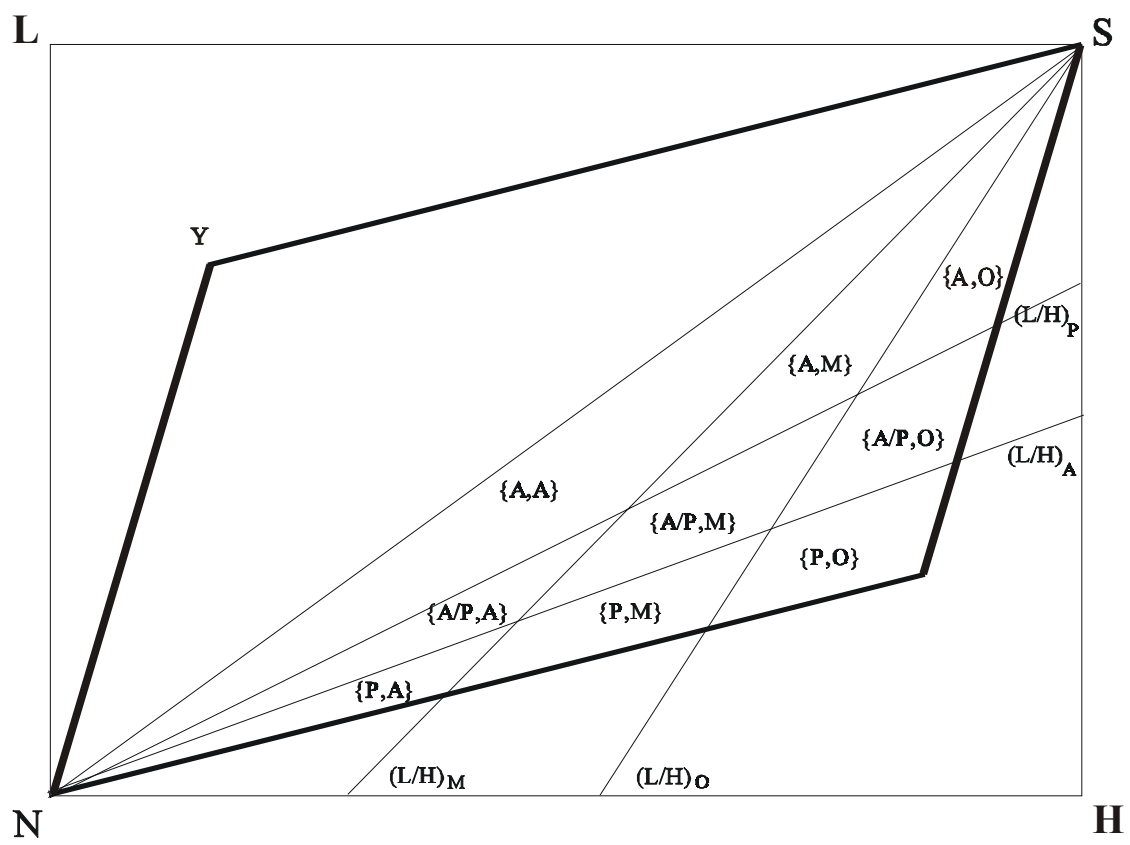

Figure 3: Integrated World Equilibrium and Organizational Convergence 


\section{References}

[1] Aghion, P. and J. Tirole. 1997. Formal and Real Authority in Organizations. Journal of Political Economy. 105 (1). pp. 1-29.

[2] Antràs, P. 2003. Firms, Contracts, and Trade Structure. The Quarterly Journal of Economics. forthcoming.

[3] Drucker, P. 2001. The Future of the Company. The Economist. December.

[4] Feenstra, R. C. 1998. Integration of Trade and Disintegration of Production in the Global Economy. Journal of Economic Perspectives. 12. pp.31-50.

[5] Feenstra, R. C. and G. H. Hanson. 1997. Foreign Direct Investment and Relative Wages: Evidence form Mexico's Maquiladoras. Journal of International Economics. 42. pp. 371-394.

[6] Grossman, G. and E. Helpman. 2002. Integration vs. Outsourcing in Industry Equilibrium. The Quarterly Journal of Economics. 117 (1). pp. 85-120.

[7] Helpman, H. and P. Krugman. 1985. Market Structure and Foreign Trade. MIT Press, Cambridge.

[8] Holmstrom, B. and St. N. Kaplan. 2001. Corporate Governance and Merger Activity in the United States. Journal of Economic Perspectives. 15 (2). pp. 121-144.

[9] Hummels, D., J. Ishii, and K.-M. Yi. 2001. The Nature and Growth of Vertical Specialization in World Trade. Journal of International Economics. pp. 75-96.

[10] Krugman, P. 1995. Growing World Trade: Causes and Consequences. Brookings Papers on Economic Activity. 1. pp. 327-377.

[11] Lawrence, R. Z. and M. J. Slaughter. 1993. International Trade and American Wages in the 1980s: Giant Sucking Sound or Small Hiccup? Brookings Papers on Economic Activity. 2. pp. 161-227.

[12] Leamer, E. 1993. Wage Effects of a U.S.-Mexico Free Trade Agreement. in: Garber, P. M. (ed.). The Mexico-U.S. Free Trade Agreement, Cambridge: MIT Press, pp. 57-128.

[13] Marin, D. and T. Verdier. 2002. Power Inside the Firm and the Market: A General Equilibrium Approach. CEPR-Discussion Paper No. 3526, London.

[14] Rajan, R. G. and L. Zingales. 2000. The Governance of the New Corporation. in: Vives, X. (ed.). Corporate Governance. Cambridge University Press. 
[15] Rajan, R. G. and L. Zingales. 2001. The Firm as a Dedicated Hierarchy: A Theory of the Origins and Growth of Firms. The Quarterly Journal of Economics 116 (3). pp. 805-852.

[16] Yi, K.-M. 2003. Can Vertical Specialization Explain the Growth of World Trade? Journal of Political Economy. 111 (1). pp. 52-102. 